\title{
An Overview of Water Birth and Its Benefits
}

\author{
Chandraleka Ravi ${ }^{1}$, Renuka Kandasamy ${ }^{2}$
}

\begin{abstract}
Birth is a dynamic process and joyful process where every woman who is pregnant will definitely undergo the delivery process. The process of delivery will be normal, Cesarean section, vacuum, and forceps methods. Most of the mothers who are all undergone for normal spontaneous vaginal delivery process will get an episiotomy wound, especially the primigravid mothers. Some mothers may develop complications like irregular shape of the perineal region, pain, and wound infection. In that, many women need different birthing methods which will lower the labor pain and complications. Water birth is an emerging alternative method of delivery process with fewer complications. In water birth, there is no need for performance of episiotomy even for primigravid mothers. Because of less awareness among people, the practice of water birth was not popular. Training will be provided for the midwives to conduct an efficient water birth for the pregnant mothers, and the students will be educated and practiced in their study period itself. Further research studies are required to bring out the water birth into practice.

Keywords: Labor pain, Primigravid, Water birth.

Pondicherry Journal of Nursing (2021): 10.5005/jp-journals-10084-13120
\end{abstract}

\section{INTRODUCTION}

Over the past 50 years, the healthcare system has done many changes in taking care of mothers during perinatal period. Some of the practices are included during the labor to reduce complications at the time of intranatal period, it may include an attempt for a trial labor after a previous Cesarean section, presence of family member during labor and birth, and management of pain during labor. For a quality outcome during perinatal period, more women and healthcare workers have suggested the water birth., ${ }^{1,2}$ Water birth is related to positive effects for the intranatal mothers which may include pain relief, relaxation from stress, buoyancy effects, which may facilitate mobility and make a sense of control; it may lead to a positive birth experience and a better neonatal outcome. Some of the randomized controlled studies with water birth had reported that most of the mothers during the intranatal period had a shorter period of the first stage of labor and showed a less need for anesthesia. ${ }^{3,4}$ Laboring in water or water birth can help the mother to overcome the stress by increasing the level of endorphin, aiding relaxation, and reducing the perception of pain level. ${ }^{5}$

\section{Literature Review on Water Birth}

Snapp et al. conducted a descriptive correlational study on "The experience of land and water birth within the American Association of Birth Centers Perinatal Data Registry, 2012-2017" had reported that more number of women who have delivered in water had less chance of getting fetal heart rate abnormalities, genital lacerations, shoulder dystocias, hemorrhage, episiotomies, postpartum transfers, neonatal intensive care unit (NICU) admissions of neonates, and shorter first and second stages of labor. ${ }^{6}$ Ulfsdottir et al. conducted a retrospective cohort study of "Waterbirth in Sweden-a comparative study" and they have compared the characteristics and outcomes of water birth with those of spontaneous vaginal delivery. The study has concluded that women who have undergone water birth have a lower risk of perineal tear, shortened labor, and need fewer interventions than the comparison group. ${ }^{7}$ Lewis et al. conducted an exploratory design on "The perceptions and experiences of women who
'Department of Obstetrics and Gynecology, Kasturba Gandhi Nursing College, Puducherry, India

${ }^{2}$ Department of Medical Surgical Nursing, Kasturba Gandhi Nursing College, Puducherry, India

Corresponding Author: Chandraleka Ravi, Department of Obstetrics and Gynecology, Kasturba Gandhi Nursing College, Puducherry, India, Phone: +91 8056499442, e-mail: rchandraleka8294@gmail.com

How to cite this article: Ravi C, Kandasamy R. An Overview of Water Birth and Its Benefits. Pon J Nurs 2021;14(4):91-93.

Source of support: Nil

Conflict of interest: None

achieved and did not achieve a waterbirth" in Australia. They have reported that the mothers who have achieved water birth have experienced fewer complications like reduced pain during their intranatal and postnatal periods and a relaxed environment when compared to the mother's who did not experience water birth. ${ }^{8}$

\section{Indication for Water Birth}

- A mother who has willing to deliver their baby by water birth after giving informed consent.

- Term mothers or mothers more than 37 weeks of gestation who are at low risk.

\section{Contraindications for Water Birth}

- Excessive hemorrhage during intranatal period.

- Meconium stained.

- Irregular or absence of fetal heart rate.

- Hyperthermia of the mother.

- Mother with communicable diseases that will affect the baby during delivery.

- Premature rupture of membrane.

- Mothers who are under sedation.

- Less capability of the midwife to prevent and manage complications. ${ }^{9}$ 


\section{Advantages of Water Birth}

\section{For Maternal Side}

- The water birth may increase satisfaction with their childbirth. ${ }^{10}$

- It may reduce the level of perception of pain among the mothers during intranatal period, and it will increase the endorphin release and provide relaxation to the mother. ${ }^{11}$

- During water birth, the catecholamine and stress hormone levels will be decreased which leads to shorten the first and second stages of labor, thereby progressing the labor process. ${ }^{12}$

- During water birth, the mother can be in various birth positions and it can lead to increased diameter of the true pelvis. ${ }^{13}$

- Water birth can lower the chance of getting pharmacologic pain relief. $^{3}$

- Water birth can reduce the risk of getting perineal trauma and postpartum hemorrhage. ${ }^{13}$

\section{For Fetal Side}

- Breathing or drowning:

"Barbara Harper, the director of Waterbirth International, has explained about many factors which will inhibit the fetus from water inhalation during the birthing process. They have explained that the fetus will have increased secretion of prostaglandin E2 from the placenta before 24-48 hours of the onset of spontaneous labor. This process may lead to decreased fetal breathing movement, and the diaphragm will help to increase the blood flow to the vital organ. After delivery, the baby will still have increased prostaglandin E2 which makes the baby's breathing muscle not to work. So the baby will not engulf the water. After removing from the water, the baby will start to breathe. ${ }^{14}$

\section{Complications of Water Birth}

Cord avulsion is a rare complication which may occur during water birth.

\section{Common Types of Hydrotherapy for Pregnant Mothers}

Hydrotherapy can be used in a variety of ways, but the three most common methods utilized during pregnancy and labor are:

- Taking a hot bath or shower: Hydrating in a warm shower can help to relax fatigued muscles, which can be especially helpful as they expand and contract during delivery.

- During labor, use a water spray: In the middle of a contraction, a water spray on the face of the mother can help to stay calm and cool. A cool compress will help you breathe easier and boost metabolism, whereas a warm compress, particularly when applied to the back muscles or pelvis, can help reduce muscular tension between contractions.

- Immersion of the entire body: Some mothers are lured to hydrotherapy to the point that they give birth in a warm tub. Floating is supposed to relieve strain on the vertebrae and assist the pelvis to expand up when it has been needed the most, reducing contractions and easing labor discomfort. ${ }^{15}$

\section{Other Types}

Hydrotherapy comes in a variety of forms:

\section{Aquatic or Whirlpool Therapy}

A physical therapist or aquatic therapist will provide this form of hydrotherapy. Depending on the outcomes desired, a therapist may employ alternative positions or approaches.

\section{Contrast Bath}

As the name implies, this involves alternately using cooling water flow baths. Pain, edema, and inflammation have all been shown to be reduced by contrast baths.

\section{Hydro-massage}

High-pressure jets are frequently used in hydro-massage. This aids in both pain relief and relaxation.

\section{Spas}

Baths, pools, showers, and whirlpools are all examples of spas. They are frequently unattended and can be used for entertainment.

\section{Kneipp System}

The Kneipp System named after its creator, Father Sebastian Kneipp, combines herbal and mineral showers with various water temperatures. In combination with a detoxifying diet or religious life, this has a variety of health benefits. ${ }^{16}$

\section{Conclusion}

Water birth is a simple method of childbirth with fewer complications. Water birth can give less pain to the mother and the chance of getting episiotomy is very low. And also, it will not develop more complications to the maternal and the fetal side. Because of less awareness, the practice of water birth is very low in our country. So this review concluded that further studies are required to bring out the change in childbirth and make the practice of water birth with the help of midwifery.

\section{References}

1. The American College of Ostetricians and Gynecologists. Committee Opinion. 679. Summary: immersion in water during labor and delivery. Obstet Gynecol 2016;128(5):1198-1199. DOI: 10.1097/ AOG.0000000000001765.

2. American Academy of Pediatrics. Immersion in water during labor and delivery. Pediatrics 2014;133(4):758-761. DOI: 10.1542/Peds.20133794.

3. Cluett ER, Burns E. Immersion in water in labour and birth. Cochrane Database Syst Rev 2009;2:CD000111. DOI: 10.1002/14651858. CD000111.pub3.

4. Richmond H. Women's experience of waterbirth. Pract Midwife 2003;6(3):26-31. PMID: 12677840.

5. Mollamahmutoğlu L, Moraloğlu O, Ozyer S, Su FA, Karayalçın R, Hançerlioğlu $\mathrm{N}$, et al. The effects of immersion in water on labor, birth and newborn and comparison with epidural analgesia and conventional vaginal delivery. J Turk German Gynecol Assoc 2012;13(1):45-49. DOI: 10.5152/jtgga.2012.03.

6. Snapp C, Stapleton SR, Wright J, Niemczyk NA, Jolles D. The experience of land and water birth within the American Association of Birth Centers Perinatal Data Registry, 2012-2017. J Perinat Neonatal Nurs 2020;34(1):16-26. DOI: 10.1097/JPN.0000000000000450.

7. Ulfsdottir H, Saltvedt S, Georgsson S. Comparative study about characteristics and outcomes of waterbirth with those of spontaneous vaginal delivery in Sweden. Acta Obstet Gynecol Scand 2018;97(3):341-348. DOI: 10.1111/aogs.13286.

8. Lewis L, Hauck YL, Crichton C, Barnes C, Poletti C, Overing H, et al. The perceptions and experiences of women who achieved and did not achieve a waterbirth in Australia. BMC Pregnancy Childbirth 2018;18(1):23. DOI: 10.1186/s 12884-017-1637-5.

9. Arizona Department of Health Services. Guidelines for water immersion and water birth. 2016. p. 8.

10. Spragne A. Water labour, water birth: a guide to the use of water during childbirth: a guide to the use of water during pregnancy labour and birth. 4th ed. 2011. 
11. Avery MD. Supporting a physiologic approach to pregnancy and birth: a practical Guide. Wiley-Blackwell Publishing; 2013.

12. Dahlen HG, Dowling H, Tracy M, Schmied V, Tracy S. Maternal and perinatal outcomes amongst low risk women giving birth in water compared to six birth positions on land. A descriptive cross sectional study in a birth center over 12 years. Midwifery 2013;29(7):759-764. DOI: 10.1016/j.midw.2012.07.002.

13. Harper B. In deep: seven secrets of successful waterbirth. Essentially MIDIRS 2012;3(5):32-37.
14. Schafer R. Umbilical cord avulsion in waterbirth. J Midwifery Women Health 2014;59(1):91-94. DOI: 10.1111/jmwh.12157.

15. What hydrotherapy does during pregnancy and labor. What to expect. Available from: https://www.whattoexpect.com/ pregnancy-and-hydrotherapy.aspx [Accessed October 10, 2021].

16. Hydrotherapy treatment, benefits, types \& contraindications. HomeCEUConnection. 2018. Available from: https://www. homeceuconnection.com/blog/hydrotherapy-treatment-benefitstypes-contraindications/. 